\title{
Crise mundial e reestruturação produtiva: algumas questões de ordem teórica
}

Alex Fiúza de Mello - Professor do Programa de Pós-Graduação em Ciências Sociais do CFCH, da Universidade Federal do Pará (CFCH-UFPA)

\section{Resumo}

A crise do padrão de acumulação que sustentou o crescimento intensivo capitalista desde o pós-guerra até a virada dos anos 70 tem suscitado, ao longo das últimas décadas, inúmeros esforços teóricos para compreender/explicar as causas histórico/ sociológicas (econômico/políticas) presentes na raiz de todo este processo. O presente trabalho propõe-se levantar algumas questões de ordem teórica mais geral, atentando para o fato de que a nova crise, que é também uma crise de acumulação, ocorre no contexto de um capitalismo de bases produtivo- institucionais já globalizadas, o que exige novos desenvolvimentos teóricos e novas abordagens para o que tem sido denominado "nova reestruturação produtiva".

\section{Abstract}

The crisis of the accumulation pattern that supported the intensive capitalistic growth since post-war period until the beginning of the seventies has suscitated along the last decades some theoretical efforts to realize/explain the historical/sociological (economical/political) causes present in the root of this process as a whole. This paper aims to raise some questions of more general thoretical order, considering the fact that the new crisis, which is also a crisis of accumulation, occurs in the context of a capitalism organized in a global productive basis, what claims for new theoretical developments and new approachs respect to that has been called "new productive restructuration".

\section{Palavras-chave}

Globalização, trabalho, reestruturação produtiva.

\section{Keywords}

Globalization, work, productive restructuration. 


\section{1 - REESTRUTURAÇÃO PRODUTIVA, CRISE MUNDIAL E CAPITALISMO}

A história do capitalismo é a história da constante e permanente reestruturação produtiva. Desde que a expansão do comércio ultramarino no século XVI e a conseqüente constituição de um mercado mundial ao longo dos séculos subseqüentes passaram a tensionar (subsumindo-os) os padrões produtivos herdados do medievo europeu e de outros modos de produção pré-capitalistas presentes nos demais quadrantes do globo, nunca mais se teve trégua no que até então podia ser considerado (comparativamente) como o pacato e estável reino da produção de valores-de-uso. O império universal da mercadoria, plasmado culturalmente pelo frenesi da concorrência (MARX, 1986, p. 366) (que é a lógica do matar ou morrer, da conquista crescente de mercados ou da condenação irremediável à bancarrota), decretara de uma vez por todas, since its earlier days, a lei áurea de toda a novíssima engenharia social nascente: a obrigatoriedade da produtividade máxima (e com ela a necessidade da busca ininterrupta da inovação), o combustível por excelência da máquina civilizatória moderna, de sua potência expansionista e mundializante, substrato material da onda de revolução permanente que se precipitou em direção aos horizontes curvos do planeta, subordinando todos os povos e raças, tribos e nações aos imperativos da racionalidade da acumulação e do lucro. Desde lá as transformações não cessaram: cooperação simples, manufatura, grande indústria, revoluções sucessivas nos meios de transporte e de comunicação e nos padrões industriais de produção graças à aplicação tecnológica das conquistas da ciência moderna everyway and everywhere (passagens pela mecânica, eletricidade, eletrônica, microeletrônica, etc.), taylorismo, fordismo, toyotismo, livre-concorrência e monopolismo, concentração, centralização, inter/multi/trans/nacionalização do capital, tudo num continuumcrescente, historicamente articulado emumúnico egigantesco processo de "ocidentalização do mundo" ou de "mundialização do Ocidente", que, na essência, confunde-se com (e traduz) o movimento paulatino de constituição do capitalismo enquanto sistema mundial, desde suas origens quinhentistas/ seiscentistas, fundado numa dinâmica progressivamente transcontinental de institucionalidade, configurada de forma combinada (ainda que desigual) em fases e escalas distintas e sucessivas de desenvolvimento cada vez mais alargado em sua materialização societária (colonialismo, imperialismo, globalismo), conforme as necessidades de expansão e/ou reestruturação do mercado mundial e da reprodução ampliada do capital.

Com o tempo, o modo de produção capitalista foi se revelando como um modo de produção não apenas de mercadorias e/ou de maisvalia (versão moderna de técnica de extorsão do sobretrabalho humano). Constituiu-se também, historicamente, day by day, um modo de produção mundial. Um sistema econômico empiricamente articulado em diâmetro 
planetário, embrionariamente forjado desde os mais remotos e insondáveis processos (violentos) de acumulação primitiva deflagrados nos albores do mercantilismo, quando a Europa fornecia navios e exportações, a América e a Ásia, ouro e prata e matérias-primas, e a África, mercadoria humana. Deslocado o olhar para os séculos XVIII e XIX, ver-se-á que tudo já estava, de alguma forma, definitivamente interligado: o boom de desenvolvimento da indústria náutica na Europa fora resultado direto da abertura do canal do Suez que liberou o tráfego a vapor para a Ásia Oriental; as conquistas na técnica de produção do ferro e do aço desenvolvidas por firmas distintas na Alemanha e na Inglaterra (reduzindo a um mínimo o tempo de trabalho e os custos de operação exigidos pelos métodos anteriores) logo transformaram por completo o padrão tecnológico internacional até então dominante no ramo; as revoluções nos transportes e nas comunicações, ao aproximarem de 70 a 90\% a América e a Índia dos países industrializados europeus, reduziram naqueles países grande parte de sua capacidade social explosiva (MARX, 1981, p. 163-164) and so on. Não é, portanto, exclusividade do século XX a configuração de um cenário em que a dinâmica social, marcada por circuitos mundializados de interação, produz transformações em cadeia no conjunto do sistema a partir de modificações mais moleculares em suas partes (ou instâncias) constitutivas e (vice-versa) provoca alterações nas várias instâncias particulares por efeito da dinâmica mais geral da estrutura socioeconômica global em movimento, pela ebulição e pela intensificação de suas leis internas de desenvolvimento. Se, no limiar do século XV, o começo do domínio da arte de navegação de longa distância destacavase, por um lado, como um evento particular que coroava de êxito as iniciativas e a vontade de poder de uma burguesia comercial européia emergente (associada às monarquias), que há muito ambicionava por novas fontes alternativas de riqueza, por outro, após as primeiras aventuras de além-mar, a caravela logo se transformou no instrumento decisivo de uma revolução mundial que conduziu à superação, pelas conquistas e pelos efeitos do comércio, da antiga sociabilidade de "pequena esquina do globo" (SWEEZY, 1972). Da mesma forma, a típica oficina moderna, fabril, mecanizada, brotada originariamente em solo inglês em meados do século XVIII, ao mesmo tempo que, enquanto particularidade, é um fenômeno decorrente da multiplicação das necessidades sociais geradas pela amplificação do processo de mundialização das relações de troca (portanto da pressão exercida pela expansão do mercado sobre as bases produtivas até então vigentes), é também causa e anúncio do mais gigantesco e revolucionário processo de reestruturação produtiva global de que se tem notícia na história: a 
revolução industrial. No contexto de um modo de produção que já nasce tensionado pelas interpelações de um mercado de efervescência supranacional, que se desenvolve como uma teia que vai costurando cada canto da Terra em um único e imenso organismo voltado para a produção de mercadorias, que se consolida como um sistema mundial fortemente articulado e interdependente (ainda que de maneira desigual), toda a dinâmica social vigente e suas manifestações fenomênicas mais salientes (das grandes inovações tecnológicas e de padrões de consumo às formas institucionais de organização do poder político), como a sucessão cíclica de períodos de crescimento econômico e de crise generalizada, já não constituem senão expressões dessa cadeia mais alargada de interacionismo, na qual necessidades e interesses, demandas e ofertas, inovações e contradições já estão de alguma forma condicionados, em ritmo e em grau, pelo metabolismo mundializado de funcionamento do sistema como um todo, determinado em última instância pelos imperativos da reprodução ampliada do capital, de suas estratégias de acumulação e de lucratividade.

As crises cíclicas nada mais são que expressão (causa e efeito) desse mesmo movimento contraditório de acumulação e expansão contínua das forças produtivas capitalistas em suas várias etapas de desenvolvimento e têm representado, sempre, momentos de reajuste da economia mundial dadas essas necessidades. E isso deriva da própria natureza contraditória do movimento de autovalorização do capital que, por fazer depender a realização da massa do valor gerado de sua contínua absorção pelo mercado, ao estender de tempos em tempos a oferta de produtos para além dos limites possíveis da demanda conjuntural, acaba por gerar, nesses contextos, uma superprodução de mercadorias (com a conseqüente depreciação dos preços), que passa a exigir a ampliação contínua de mercados. "No modo capitalista de produção - argúi Marx - (1981, p. 375), relativamente à população, desenvolve-se em demasia a produtividade, e, embora sem atingir a mesma proporção, aumentam os valores-capital (e não só o substrato material desses valores) de maneira mais rápida que a população. Os dois fatos colidem com a base - que, em relação à riqueza crescente, é cada vez mais estreita, e para a qual opera essa produtividade imensa - e com as condições de valorização do capital que se expande. Daí as crises". Bukharine, que compreendeu corretamente o conteúdo da tese da superprodução, de Marx, ao destacar a qualidade relativa (e não absoluta) do fenômeno da superprodução, no qual o excesso de produção se dá relativamente à procura efetiva (possibilidade social de pagamento) e não em função das necessidades sociais absolutas, atentou para o fato de que, por ser a produção do capital uma produção de mercadorias produzidas 
capitalisticamente, toda crise revela uma desproporção temporária (e que acaba sendo estrutural) entre oferta e procura, entre necessidade de expansão da produção (e sua realização) e capacidade social de consumo, coincidindo conseqüentemente toda superprodução de capital com uma superprodução de mercadorias (BUKHARINE, 1976, p. 271292).

As sucessivas "epidemias de superprodução" que passaram a irromper a partir de meados do século XIX (momento de consolidação da revolução industrial), afetando o conjunto do sistema capitalista, já não mais figuravam (já àquela altura) como simples ocorrências locais, nacionais ou até mesmo "européias". Desde então, essas crises, como poderes infernais que escaparam do controle do feiticeiro, transbordam para todos os lados, sob a forma de "dejetos sociais", os acúmulos do "excesso de civilização" que já não cabem no recipiente limitado da propriedade burguesa: falências, desemprego, pauperismo, subconsumo, violência e toda sorte de barbarismo. Ao abalar indistintamente e de forma combinada (ainda que desigual) os vários níveis, instâncias, setores e organizações da vida social em todas as zonas e regiões do planeta, as periódicas e permanentes crises sistêmicas, como sintomas sensíveis que emergem na epiderme da complexa tecitura do organismo da sociedade global, manifestam em toda a sua crueza o estádio avançado de uma guerra molecular de dimensões universais, confirmando o diagnóstico de que, no mundo moderno, o processamento da dinâmica e o alcance das contradições entre os homens não se dá mais sob outra forma que aquela generalizada e incontrolável da "metástase". "As crises comerciais que se manifestam durante o século XIX, em particular as grandes crises de 1825 e 1836 observara Marx (1977, p. 170) - já não eram fenômenos econômicos isolados [...] eram agora grandes tempestades do mercado mundial onde explodia o conflito entre todos os elementos do processo de produção burguesa". Ou seja, num sistema de produção mercantil de funcionamento mundialmente articulado, no qual a saúde do conjunto do sistema passa a depender de cada veia particular por onde flui a circulação que dá vida ao organismo, cada impasse ou problema proveniente de qualquer zona restrita do circuito atinge necessariamente o organismo como um todo. Assim, as crises colossais que se abatiam sobre as nações européias desde a entrada do século XIX nada mais faziam do que dar o primeiro testemunho vivo e empiricamente insuspeito de que o modo capitalista de produção já vinha se transformando num gigantesco sistema de engrenagens mundializadas: uma crise financeira gerada no comércio com a Índia podia causar efeitos mais catastróficos à Grã-Bretanha, e negócios mais "sujos" nos 
bastidores da política, que os acontecimentos trágicos vividos pela guerra militar indiana (MARX; ENGELS, 1975 , p. 215-216); uma retração do livre acesso dos interesses europeus ao magnífico mercado asiático já era motivo de aproximação entre tradicionais inimigos, como a Inglaterra e a França, unidos em campanhas belicosas comuns contra o "Celeste Império", em nome da "ética e da civilização" (MARX; ENGELS, 1975, p. 92-96); uma sobreprodução nos mercados da Índia e da China já afetava diretamente o estado da Bolsa de Londres (MARX; ENGELS, 1975, p. 142), o termômetro financeiro do sistema capitalista no século XIX.

Reestruturação produtiva e crise mundial devem, pois, antes de mais nada, como a própria história tem demonstrado, ser tomadas como aspectos estruturalmente constitutivos da própria lei geral de desenvolvimento do capitalismo enquanto sistema mundial, como fenômenos decorrentes da própria tensão constante imposta pela concorrência no jogo de mercado, que impele os vários capitais a expandir-se e a transformar-se continuamente por meio da acumulação progressiva, frenética e sem tréguas, na qual o ataque (com todos os riscos de "excessos" inerentes) apresenta-se como a única defesa possível, a única tática efetiva de sobrevivência nesse incomensurável campo de guerra (entre classes e entre capitais). E, como cada acumulação torna-se meio para nova acumulação, cresce continuamente a massa de capital, a base da produção em grande escala e a concentração de riquezas, deslocando a todo instante a escala em que se realiza a concorrência em geral, de muitos capitais pequenos para poucos capitais gigantes (centralização), do plano nacional para o plano mundial (mundialização), preparando assim, na esteira do processo, crises de incidência cada vez mais globalizada, contradições de efeito cada vez mais universal.

\section{2 - O SÉCULO XX E A CONFIGURAÇÃO DO CAPITALISMO MUNDIAL}

O modo de produção capitalista mundial constituiu-se por etapas. O século XIX testemunhou a passagem do capitalismo comercial ao capitalismo industrial; o século XX, a passagem do capitalismo industrial (financeiro), estabelecido originalmente em bases localizadas (nacionais), à inter/trans/nacionalização dessas bases. A mundialização do comércio (iniciada no Quinhentos) demarcara os quatro primeiros séculos de efervescência do capitalismo e de sua organização enquanto sistema mundial, por meio da constituição progressiva de um mercado de dimensões planetárias (ainda que precariamente consolidado à época) que garantiu, graças ao sistema colonial imposto aos quatro cantos do globo pela Europa, o fluxo necessário de matérias-primas e de produtos 
requeridos pela acumulação do capital naquele período. Com o advento da revolução industrial, o agigantamento das empresas e as novas necessidades de acumulação capitalista, a mundialização da produção (que veio também por etapas) passou então a impor-se como tarefa inadiável ao grande capital formado, tendo em vista a necessidade de expansão da produção para o mercado e do próprio mercado consumidor, o que ocasionou inicialmente a exportação de inteiros setores fabris para países periféricos a partir do final do século XIX e início do XX.

O imperialismo clássico (até a II Guerra Mundial) representou o primeiro movimento de expansão do grande capital industrial por via da exportação extensiva de suas bases produtivas originariamente européias (e depois americanas e japonesas) para o resto do mundo, traduzindo os primeiros esforços de superação da relativa imobilidade internacional do capital produtivo herdada da era da livre concorrência, quando a concentração se dera basicamente nas esferas nacionais. A transferência em massa do capital oligopólico para antigas zonas de colonização - ao que Lênin chamava de cartelização do mercado mundial por gigantescas "empresas combinadas" (LÊENIN, 1977) - levou o sistema capitalista mundial a ingressar numa nova fase do processo de concentração do capital, agora escalonado em nível internacional, no qual trusts e companhias monopolistas concorrentes, em associação com estados imperialistas (da mesma forma que a burguesia mercantilista se associara às monarquias no passado), passaram a controlar ramos inteiros da produção industrial nas mais diferentes regiões do globo, partilhando entre si o mercado mundial segundo zonas específicas de influência (MANDEL, 1993).

Não demorou muito, como se sabe, para que as barreiras interpostas pela disputa imperialista se revelassem insuportáveis impedimentos à acumulação capitalista. Tais limites, estampados nas inúmeras e colossais recessões, crises e guerras mundiais que se sucederam ininterruptamente ao longo de toda a primeira metade do século XX, ameaçando a sobrevivência do próprio sistema - além da Revolução de 1917 (e as que a ela se seguiram), que subtraiu temporariamente parte do mercado mundial à influência direta desses oligopólios -, tiveram de ser revistos e superados. A fase do pós-guerra, apoiada na chamada terceira revolução tecnológica, marcaria uma reviravolta crucial nas estratégias de acumulação, na medida em que o capital completa a tarefa histórica de sua definitiva internacionalização (e que, na verdade, apresenta-se, ultima ratio, como um movimento de transnacionalização): a internacionalização das próprias empresas oligopólicas, sua centralização (e não mais apenas concentração) em escala inter/trans/nacional. Surgem as companhias multinacionais, a nova 
formatação avançada do grande capital, combinando ramos e negócios situados em diferentes países em unidades produtivo-gerenciais autônomas, mundialmente articuladas, com o que se instala um movimento crescente e permanente de integração vertical da economia, a partir do qual a nova divisão internacional dos processos de produção pouco a pouco deixa de se dar (como tradicionalmente) entre nações propriamente ditas (ainda que elas continuem a desempenhar papéis fundamentais na organização do sistema, só que agora sob forma subsumida), para se estebelecer no contexto das grandes cadeias internas das firmas transnacionalizadas - o capital mundial imediato, no dizer de Kurz (1993a) -, cuja dinâmica já rompeu definitivamente o controle dos sistemas econômicos nacionais.

O capitalismo mundial, ou o capitalismo global, vai assumindo então a conotação conceitual de uma nova etapa de dinamização da economia mundial, caracterizada pela libertação das "forças do mercado" dos entraves interpostos ao movimento dos negócios durante mais de meio século pela divisão imperialista clássica, que respondem à mundialização das bases produtivas do capital cada vez mais concentradas e centralizadas em patamar transnacional, em que os fluxos de trocas internas às firmas gigantes - além das novas combinações entre os investimentos internacionais, a colaboração recíproca (para além da concorrência) entre grandes empresas oligopólicas e uma maior racionalização de operações em escala mundial - passam a impor, em contrapartida, a necessidade de uma reestuturação radical de todo o sistema político-institucional (estatal) e econômicofinanceiro internacional, atualizando-o e afinando-o com o novo momento do processo mundial de acumulação do capital (CHESNAIS, 1994, p. 15-28). Novas estratégias voltadas para uma maior mobilidade do capital transnacional passam então a combinar uma gama de atividades transfronteiras: exportações e abastecimento no estrangeiro, investimentos diretos em regiões fora do eixo tradicional dos países centrais, alianças internacionais, novas ondas de fusões interempresariais no âmbito supranacional, diversificações das operações nos planos locais de produção, com reestruturação da divisão do trabalho e especializações regionalizadas, e assim por diante, tudo visando agilizar a capacidade instalada de mobilização e flexibilização do grande capital produtivo mundializado, aquela de engajar-se e desengajar-se, investir e desinvestir, aglutinar e subcontratar ("terceirização"), implantar-se e desenraizar-se, conforme cada contexto e oportunidade (CHESNAIS, 1994). 
A escola francesa que se dedicou (sobretudo entre as décadas de 70 e 80) à abordagem da temática (como Palloix, Michalet, Vernon, Brender, Beaud e outros) adotou inicialmente o conceito de "mundialização" ao invés daquele de "globalização" (globalization, mais vinculado à tradição anglo-saxã), o que levou a consagrar (particularmente no campo dos estudos econômicos) a expressão "capitalismo mundial" como significante de uma nova era de desenvolvimento e estruturação do capital, ou, no mínimo, como um momento histórico singular e diferenciado de sua dinâmica acumulativa. Nesse sentido, a operacionalização da idéia de "globalismo", associada ao conceito de "capitalismo mundial", enquanto categoria definidora de uma etapa diferenciada na história do capitalismo, veio ganhando força graças a essas contribuições teóricas, as quais passaram a apontar desdobramentos inéditos da expansão global do capital, hoje tornados ainda mais evidentes sobretudo após o fim da Guerra Fria, a débâcle soviética e a incorporação do Leste europeu e do restante da Ásia (incluída a China) à influência direta das companhias transnacionais - isto é, à contabilidade da produção global da mais-valia. Nesse contexto, o capital produtivo transnacional é a figura proeminente do capitalismo mundial, é o elemento dinâmico central da etapa do globalismo capitalista. É a consumação definitiva da passagem da etapa da internacionalização do intercâmbio de mercadorias àquela da internacionalização da produção, outrora inaugurada pelo imperialismo (que então pode ser visto como fase intermediária entre um momento e outro), internacionalização que, em seguida, metamorfoseia-se em transnacionalização, espécie de nova formatação do dinamismo e da composição do capital em sua nova fase de concentração/centralização. Isso está muito bem caracterizado, por exemplo, no trabalho de Charles-Albert Michalet, para quem, na etapa do capitalismo mundial, é a empresa multinacional que passa a ser o emblema da nova natureza transnacional do capital e, portanto, da superação do estado-nação como artífice primordial da dinâmica mundial da acumulação capitalista. Em seu Le capitalisme mondial (1976), Michalet entende que, após a II Grande Guerra, o capitalismo avançou na consolidação de uma etapa superior de sua evolução, na qual a produção em geral, deslocada para o interior desterritorializado das nações periféricas, graças à ação de capitais transnacionalizados, passa a ter o primado definitivo sobre a circulação internacional de mercadorias, instaurando-se um novo patamar de reprodução do capital que subverte a antiga ordem econômica internacional e forma correspondente de dinâmica capitalista. As empresas multinacionais (EM), enquanto encarnações institucionais dessa nova lógica de funcionamento do capital transnacionalizado, constituir-se-iam, assim, 
na expressão material da nova base de existência e racionalidade da ação capitalista, como que engendrando um sistema historicamente inédito de interação global - entendido como nova totalidade em via de formação -, no qual o ritmo e a natureza da produção e da circulação de mercadorias escapam inteiramente às determinações do espaço nacional tradicional para se processarem no interior de um novo circuito homogêneo transnacionalizado (as EM), no âmbito do qual transitam bens, serviços, homens, conhecimentos e tecnologias. A centralização da produção dos conhecimentos científicos e técnicos, a circulação interna de tecnologia (por via de assistência técnica padronizada e deslocamento da pesquisa por "laboratórios-ateliers" locais) e a difusão externa dos padrões tecnológicos gerados expressariam, por assim dizer, momentos/ estratégias da nova dialética do capitalismo mundial, da "unidadedisparidade" de um novo estágio em que a simultânea exploração/ negação das diferenças de nível de desenvolvimento entre nações e regiões (tendentes para uma homogeneização transversal) refletiria "a passagem de um 'modelo' dominado pela realização da mais-valia através da circulação internacional das mercadorias e dos capitais, a um 'modelo' caracterizado pelo deslocamento do processo de extração da mais-valia" (MICHALET, 1976, p. 224), agora transferido também para regiões menos desenvolvidas do planeta (espécie de nichos produtivos sob o controle das matrizes) onde, em última instância, as taxas diferenciais de exploração da força de trabalho colocariam em vantagem competitiva os capitais que adotam tal estratégia produtiva em comparação àqueles que permanecem limitados pela simples estratégia comercial.

Essa tendência do capitalismo vislumbrada por Michalet - seu, por assim dizer, "lugar teórico de ruptura" - apóia-se e inspira-se no diálogo e no debate que estabelece não apenas com autores mais recentes da economia política contemporânea (R. Vernon, S. Humer, além de Palloix, S. Amin e outros), mas sobretudo com as fontes clássicas do marxismo, basicamente Karl Marx e, a partir dele, Rosa Luxemburgo e Lênin. É interessante notar que Michalet parte de uma crítica aos limites de boa parte da análise marxista clássica (sobretudo aquela inspirada em Rosa Luxemburgo, etc.), que trabalha preponderantemente com a noção de "Estado-nação" (a exemplo da teoria neoclássica de Ricardo e Adam Smith) e que fica circunscrita ao campo da análise do comércio internacional (em que a circulação é privilegiada enquanto esfera na qual se realiza o movimento do capital), e vai à fonte de toda a reflexão marxista, resgata a contribuição de Marx, para quem privilegiar a esfera do comércio 
internacional traduz apenas o estádio concorrencial ao qual havia chegado o capitalismo em meados do século XIX - e não todas as suas potencialidades de desenvolvimento acumulativo -, fundamentando-se nessa tese para elaborar novos conceitos e noções, teórica e metodologicamente mais adaptados às exigências da nova configuração do capitalismo mundial. Michalet credita à noção leninista de imperialismo uma primeira ruptura importante com a teoria tradicional, na medida em que, superando os limites da circulação de mercadorias, "estabelece as bases de uma nova concepção de economia internacional, a partir da extensão à escala mundial do MPC" (MICHALET, 1976, p. 64). A compreensão de Lênin sobre as conexões entre o capitalismo monopolista e a exportação de capitais permite-lhe, segundo Michalet, explicar o movimento da capitais para o exterior, inaugurando um novo ciclo de lucratividade, superior ao dos investimentos locais típicos da fase concorrencial. Mais do que uma nova etapa de expansão da mais-valia e do lucro, o imperialismo, então "fase superior do capitalismo", demarcaria igualmente, para Lênin, uma rearticulação e o deslocamento das relações e instâncias do poder em âmbito internacional, em que os conflitos entre os Estados subordinam-se àqueles entre os monopólios. Segundo Michalet, é a partir dessa formulação leninista que se torna possível fazer uma dupla constatação: "Primeiro, a teoria tradicional da economia internacional é, uma vez mais, colocada sob fogo cerrado: os Estados-nações já não são mais os pólos (únicos) ao redor dos quais se organizam as redes comerciais em escala mundial. Em segundo lugar, como conseqüência dessa reviravolta, os 'grupos econômicos' - complexos industriais e bancários - substituem os Estados. São esses grupos que estruturam as relações internacionais. Eles constituem a base econômica sobre a qual se constrói o sistema da economia mundial capitalista" (MICHALET, 1976, p. 69). Entretanto, esse "avanço da teoria marxista legado por Lênin tem, por seu turno - segundo Michalet -, também seus limites, visto que, embora esboce uma análise de mudança expressa na crescente importância do capital-financeiro em relação ao capital-mercadoria no estágio do monopólio (denotando aqui uma influência direta de Hilferding), epistemologicamente, circunscrever-se-ia ainda ao terreno da esfera da circulação, isto é, a uma concepção de externalidade entre os capitais produtivos e os Estados-nação. O capitalismo mundial é a fase da transnacionalização do capital produtivo, da primazia da órbita da produção, mas da produção concebida enquanto modo/sistema econômico mundializado. Daí porque, para Michalet, ainda que Lênin evidencie uma nova forma 
de exploração/dominação trazida pela exportação de capitais do centro para a periferia, não consegue romper de todo com a noção de "economia internacional", que o autor propõe substituir pela idéia de sistema econômico mundial (SEM): "o SEM deveria englobar as instâncias não-econômicas e especificar o lugar e o papel das instâncias institucionais, sócio-culturais e políticas em vias de internacionalização. Enfim, a tarefa consistiria em elaborar as especificidades da existência do MPC alargado à escala planetária [...] [orientação que deve ser] o pano de fundo de toda pesquisa que vise construir os instrumentos conceituais adequados à observação e compreensão da realidade imediata e de seus movimentos" (MICHALET, 1976, p. 94-95, grifo nosso).

O globalismoé a nova etapa do desenvolvimento do capitalismo: sua etapa superior. Mas não se trata, aqui, de imaginar que o conceito de imperialismo fique anulado (in totum). "Entretanto - como coloca O. Ianni - o globalismo subsume histórica e teoricamente (logicamente) o imperialismo, [à medida que] se trata de duas configurações históricas e teóricas distintas [...], duas totalidades diferentes, sendo que uma é mais abrangente que a outra, [ou seja], o globalismo pode conter vários imperialismos, assim como diferentes regionalismos, muitos nacionalismos e uma infinidade de localismos" (IANNI, 1996, p. 130). Nesse novo contexto, em que fenômenos como o da transnacionalidade e o da transestatalidade anunciam uma configuração material inédita do capital e de seu dinamismo global, conceitos como "sistemamundial", "capitalismo mundial", "economia-mundo", "economia global", etc. passam a ganhar teoricamente uma maior importância e centralidade, ao mesmo tempo que apontam um deslocamento heurístico necessário dos referenciais de análise, abrindo novas perspectivas de entendimento para os processos sociais em curso

\section{3 - A CRISE DOS ANOS 70/80 E A NOVA REESTRUTURAÇÃO PRODUTIVA}

Se, como já foi afimado, toda manifestação de crise e/ou de modificação nos padrões de produção deve ser encarada como elemento constitutivo da própria dinâmica do modo de ser capitalista de produção e está associada intimamente à lei geral do processo de autovalorização do capital, à sua necessidade de acumulação contínua (à sua reprodução ampliada), a crise que, reconhecidamente, foi caracterizando-se a partir dos anos 70 (para alguns desde o final dos anos 60) não foge à regra. É 
preciso, não obstante, examinar suas características específicas e o novo contexto histórico no qual se insere.

Concorda a maioria dos autores que tem se dedicado ao tema (Aglietta, Brende, Boyer, Mistral, Piore, Sabel, Harvey, etc.), descontadas (obviamente) suas diferenças e perspectivas de abordagem, que o longo período de expansão econômica que se sucedeu à Segunda Guerra Mundial esteve pautado por um modelo mundialmente articulado de expansão internacionalista da produção capitalista-industrial, que ficou conhecido como modelo fordista-keynesiano. Tratava-se de garantir um novo surto de acumulação por meio da disseminação universal de um padrão produtivo, gestado originariamente nos Estados Unidos no entreguerras (o fordismo), que envolvia a incorporação de extensas massas de trabalhadores a um regime de exploração mais intensiva do trabalho, fundado na utilização de linhas contínuas de montagem semiautomáticas no interior das fábricas, nas quais o tempo e o ritmo de execução das tarefas passaram a ser ditados pelo maquinismo e controlados diretamente pelo capital (numa espécie de desenvolvimento dos princípios propugnados pelo taylorismo). A expansão mundial do padrão fordista (que nos países periféricos assumiu a feição "nacionalista" de política de substituição de importações) propiciava ao mesmo tempo um nível mais elevado de produtividade média do trabalho (com ampliação da taxa de mais-valia, sobretudo se considerados os baixos salários pagos em países atrasados) e um crescimento considerável do mercado mundial baseado na produção de massa e no consumo de massa (que também, nos países periféricos, assumiu a feição "nacionalista" de expansão do mercado "interno"). Essa expansão mundial do padrão fordista esteve sempre associada (conforme receita de Keynes) à intervenção estratégica do Estado que era chamado a arcar com os custos mais pesados da infra-estrutura econômica (estradas, energia, comunicação, etc.) e do bem-estar social (educação, saúde, seguridade social, etc.), mantendo continuamente gastos em investimentos públicos, vitais para a sustentação do sistema de produção em massa (realização da mais-valia agregada) e dos altos índices de emprego típicos do período (parte do pacto social). "O progresso internacional do fordismo - diz Harvey (1993, p. 131) - significou a formação de mercados de massa globais e a absorção da massa da população mundial fora do mundo comunista na dinâmica global de um novo tipo de capitalismo. Além disso, o desenvolvimento desigual na economia mundial significou a experiência de ciclos econômicos já paralisados como oscilações locais e amplamente compensatórias no interior de um crescimento razoavelmente estável da demanda mundial. 
Do lado dos insumos, a abertura do comércio internacional representou a globalização da oferta de matérias-primas geralmente baratas (em particular no campo da energia). O novo internacionalismo também trouxe no seu rastro muitas outras atividades - bancos, seguros, hotéis, aeroportos e, por fim, turismo. Ele trouxe consigo uma nova cultura internacional e se apoiou fortemente em capacidades recém-descobertas de reunir, avaliar e distribuir a informação".

Produção mundial em massa, mercados globais, padrões internacionais de consumo, as realizações do fordismo-keynesianismo ao longo dos primeiros vinte e cinco anos do pós-guerra (de 1945 a 1970) representaram uma escalada ascendente na formatação mundial da sociedade em geral e no regime de acumulação capitalista em particular, padrão de crescimento que, contudo, foi pouco a pouco experimentando seus primeiros sinais de esgotamento e de crise já na virada dos anos 60 para os 70, retratados sobretudo na crise fiscal do Estado de bem-estar, que dependia da contínua aceleração da produtividade do trabalho no setor corporativo para manter o seu compromisso de fornecimento de bens coletivos (fonte de sua legitimidade). Sobrevieram então as conhecidas ondas inflacionárias, as altas taxas de desemprego, greves sindicais, movimentos sociais, o que obrigou o sistema capitalista mundial a rever o paradigma do regime de acumulação herdado do fordismo clássico e a promover inúmeras mudanças nas políticas de investimento e nas funções tradicionalmente cumpridas pelo Estado, tudo em virtude de uma reestruturação mais profunda nos padrões produtivos globais vigentes.

Superação definitiva do fordismo em curso? Não há sinais empíricos convincentes. O que significa, aliás, falar em "crise do fordismo", quando grandes empresas oligopólicas, multinacionais estão obtendo fantásticos superlucros baseados em regimes de superexploração de trabalhadores em regiões periféricas, exatamente utilizando técnicas de gestão (e padrão tecnológico) que podem ser identificados como tipicamente tayloristas / fordistas? (COLLINGSWORTH; GOOLD; HARVEY, 1994). E ainda: como falar em "modelo fordista" em geral, no âmbito de uma economia mundializada, quando a grande massa de trabalhadores explorada em países de periferia nunca teve acesso aos padrões de consumo de massa verificados nos países centrais? O problema ainda está longe de uma solução satisfatória. Nos anos 80, autores como Boyer e Mistral (afinados com as teses regulacionistas) tentavam argüir que a única saída para o impasse da crise seria a adoção de novas formas institucionais de gestão (pósfordistas), assentadas em novos mecanismos de regulação que, 
combinando padrões tecnológicos alternativos, formas de intervenção estatal e pacto social entre forças políticas opostas, assumissem novos compromissos que viessem a garantir um ciclo renovado de regime de acumulação e desenvolvimento, isto é, um novo "modo de regulação" (BOYER; MISTRAL, 1983). Sem demonstrarem como se daria isso, ficaram devendo - como toda a Escola da Regulação - uma teoria mais consistente para este "momento da transição" (que, aliás, não parece concluído). Piore e Sabel (1984), à mesma época, chegaram a imaginar que um novo surto de experiências proudhonianas de empreendimentos cooperativos de pequena escala, fundados em tecnologias descentralizadas de comando e controle (a exemplo da "Terceira Itália"), poderia representar uma alternativa às formas fordistas repressivas e dominantes de organização do trabalho (um segundo "divisor industrial"), integrando-se inicialmente a essas e até mesmo (à medida do sucesso alcançado pelo novo modelo e de sua universalização) subvertendo-as, como que num movimento de reestruturação da produção capitalista no final do século XX. Também aqui - considerados os já doze anos passados desde a formulação da tese - a história não parece ter conspirado a favor dos prognósticos propugnados. Poucos, na verdade, são os sinais que indicam qualquer mudança radical de rota no padrão dominante (mundial) de organização do processo produtivo, não obstante as incontestáveis modificações obtidas em alguns setores de ponta com a introdução de circuitos automatizados, alguma flexibilização das técnicas operativas e de controle do processo de trabalho (além daquela relativa aos padrões de consumo), além do surgimento de setores produtivos inteiramente novos, formas diferenciadas de fornecimento de serviços financeiros e de técnicas comerciais, favorecidos pelas conquistas da microeletrônica e da informática. A chamada "acumulação flexível" parece mais representar um conjunto de variações na forma de organização do processo produtivo acrescido ou mesclado aos padrões fordistas tradicionais (e isso varia conforme os ramos produtivos e/ou as regiões considerados) que propriamente apontar uma nova forma hegemônica e/ou generalizada de padrão produtivo alternativo (pós-fordista). Esse fato também é corroborado por inúmeros estudos de caso sobre empresas americanas desenvolvidos durante a primeira metade dos anos 90, cujas análises "parecem documentar que, passada quase uma década de experimentação, os exemplos de transformação bem-sucedida nos sistemas de trabalho na indústria norte-americana não são tantos quanto a difusão de nova ideologia gerencial faria esperar" (CASTRO, 1996, p. 111). 
Mudança ou não de "modo de regulação" ou de "padrão produtivo", o fato é que o sistema capitalista mundial (mesmo depois da débâcle soviética e da reincorporação do Leste europeu, que, aliás, transformou-se em área de tensão) continua a demonstrar fortes sinais de crise estrutural, sem qualquer indicativo evidente de superação a curto prazo. Muito pelo contrário, as gigantescas dívidas públicas (como a dos EUA), a crise dos sistemas bancários nacionais e internacionais e a crescente onda de desemprego estrutural estão a indicar, isto sim, uma limitação estrutural do sistema de mercado (de trabalho e de consumo) e uma retração periódica e uma crise financeira da endividada liquidez que se conjuminam na direção de uma crise global (KURZ, 1993a). Mais do que uma reestruturação nos métodos de produção (padrão tecnológico e técnicas de gestão do processo de trabalho) cujas inovações organizacionais (método Kan-Ban, etc.) Coriat chega a comparar às revoluções que significaram em sua época o taylorismo e o fordismo (CORIAT, 1994), - é a reestruturação do sistema institucional global que sustentou a estratégia keynesiana de crescimento, particularmente uma redefinição do papel do Estado e das regras internacionais de mercado, o que está determinando as transformações mais profundas em curso no momento. O capital mundial, que há trinta anos se associou aos Estados nacionais quando deles necessitava para garantir a realização de um ciclo auto-sustentado de acumulação de longo prazo, alcançado certo patamar de concentração/centralização auferido no período, hoje passa a pressionar pela "desregulamentação" e pela privatização de setores públicos - a grande bandeira neoliberal , quando o que interessa é abrir o mercado mundial e as fronteiras nacionais para o movimento livre de transações comerciais e de investimentos produtivos que passam a ser planejados e geridos nos próprios circuitos internos das grandes firmas transnacionalizadas, cuja "flexibilidade" tornou-se aquela de conseguir deslocar-se de um lugar para outro em conformidade com as vantagens locacionais oferecidas por cada região e correspondentes conjunturas políticas.

O primeiro saldo de toda essa transformação é a debilitação dos sistemas econômicos nacionais (de sua soberania para definir políticas desenvolvimentistas com base em critérios internos) em favor dos circuitos econômicos, financeiros e tecnológicos internacionalizados, articulados em função da hegemonia das empresas multinacionais (numa demonstração tácita de que talvez agora é que se vive a verdadeira "era do capital"). Nesse ritmo, como já notou Celso Furtado (1993, p. 5), "as atividades estatais tendem a circunscrever-se às áreas sociais e culturais [...] A contrapartida da internacionalização 
avassaladora é o afrouxamento dos vínculos de solidariedade histórica que unem no quadro de certas nacionalidades populações marcadas por acentuadas disparidades de nível de vida". As atenções deslocamse para os novos "mercados comuns", para os blocos regionais, que nada mais fazem que expressar um segundo estágio de organização institucional do mercado capitalista (o primeiro se deu com a criação dos Estados nacionais, apenas completado em regiões periféricas com a descolonização que se sucedeu nos anos seguintes ao pós-guerra), agora em patamar mais elevado, anunciando o progressivo movimento em cadeia da globalização irreversível da economia. Os novos critérios de alocação de recursos, de investimentos produtivos, de divisão do trabalho, de configuração de mercados já não seguem mais motivações "nacionalistas" (se é que algum dia por essas foram determinados), mas se ordenam transversalmente em âmbito global, segundo as necessidades de acumulação do capital transnacional. Da mesma forma, o gap entre ricos e pobres desloca-se pouco a pouco de desníveis intemacionais para se firmar em desníveis transnacionais de incidência. Assim, um mexicano, um brasileiro ou um indiano detentor de um cartão de crédito internacional (o novo passaporte da sociedade global) está mais próximo (ou mesmo pertence) econômica, social e culturalmente do "Primeiro Mundo", que um inglês, um francês ou um americano economicamente marginalizado (habitante das ruas de Londres, de Paris ou dos becos de Nova York) e condenado a algum estilo de vida típico de "Terceiro Mundo" (o que obriga a uma revisão desses conceitos tradicionais). No contexto do capitalismo mundial, uma crise sistêmica, que se processa em circuitos empiricamente globalizados, assume uma nova qualidade de manifestação e uma nova forma de incidência, que impõe novos ângulos de abordagem paranacionais. Aqui - diz Kurz "o conceito de sistema mundial precisa ser repensado de modo mais profundo, não mais apenas enquanto modelo de circulação na economia de mercado - como era adequado à fase das conquistas nacionais ligadas principalmente por comércio e exportação simples de capital -, mas enquanto modelo de crise do capital produtivo transnacional, em que as contradições imanentes a esse modo de produção e sua temporária suspensão através da criação não-produtiva de dinheiro reaparecem agora em nível mais global" (KURZ, 1993a, grifo nosso). Poucos têm sido, porém, até agora, os exercícios teóricos nesse sentido. As explicações para as especificidades da crise mundial no contexto do capitalismo global, desenraizadas do paradigma do Estado-nação, continuam raras; mais abundantes, nevertheless, parecem ser algumas constatações sobre os efeitos e as tendências dessa crise, sobretudo 
quando considerada a situação da classe trabalhadora no cenário em causa.

Um primeiro viés de análise que aqui pode ser destacado é o de István Mészáros, que parte de uma premissa mais geral para fundamentar seu raciocínio - a de que o sistema capitalista de produção e consumo só é capaz de reproduzir-se de forma ampliada se ocorrer pelo menos uma das seguintes condições:

1) ou o círculo de consumo se expande com sucesso, de modo a que uma ampla e crescente força de trabalho esteja capacitada para conviver com os imperativos da produtividade ampliada, absorvendo os produtos disponíveis sem dificuldade;

2) ou uma força de trabalho relativamente limitada ou estacionária (como a dos países capitalistas avançados), não obstante tal característica, consegue proporcionar uma demanda suficientemente dinâmica (altos salários) que é capaz de equilibrar a necessidade de expansão do capital gerada pelo sistema por meio da ampliação e da aceleração do índice de seu consumo (MÉSZÁROS, 1989, p. 40).

Considerando que se trata não de determinações filosóficas apriorísticas, mas de possibilidades históricas reais, Mészáros defende que, uma vez vencida uma fase de expansão mundial e estruturadas as relações orgânicas entre centros "metropolitanos" do capital e o resto do mundo (por via da subordinação deste aos interesses dos países capitalistas dominantes), "a possibilidade de ampliar o círculo de consumo, bem como a de incluir nele a população mundial como um todo, sofre um pesado impedimento" (MÉSZÁROS, 1989, p. 40-41). A saída então, nesse novo contexto, dada a tendência de expansão desproporcional entre novas faixas de consumidores e superprodução, é a implementação, pelo capital, do que o autor chama (invertendo a expressão schumpeteriana de "destruição produtiva") "produção destrutiva", ou seja, na impossibilidade de reproduzir-se o capital pela primeira via, "torna-se necessário divisar meios que possam reduzir a taxa pela qual qualquer tipo particular de mercadoria é usado, encurtando deliberadamente sua vida útil, a fim de tornar 
possível o lançamento de um contínuo suprimento de mercadorias superproduzidas no redemoinho da circulação acelerada" (MÉSZÁROS, 1989, p. 43). Nasce, então, a "sociedade descartável", que passa a lançar mão, sob inspiração de uma ética barbárica, da "desconcertante prática 'produtiva' de sucatear maquinário totalmente novo após um uso muito reduzido, ou mesmo, sem inaugurá-lo, como que para o substituir por algo 'mais avançado', ou para deixar seu lugar vago sob as condições de 'pressão descendente' na economia" (MÉSZÁROS, 1989, p. 46). Do que se depreende que - estabelecendo-se aqui um paralelo com tais formulações - o fordismo pode ser pensado como a fase de expansão (mundial) da produção em larga escala e do correspondente alargamento do mercado, que mais recentemente foi perdendo fôlego dados os novos impasses gerados pelo esgotamento desse ciclo (regime) de acumulação, com a restrição das fronteiras horizontais do mercado de consumo. Desde então, uma vez completada a incorporação do restante do planeta ao mercado mundial, só restaria ao capital (na impossibilidade de nova extensão horizontal do mercado de consumo) explorar verticalmente as potencialidades do mercado consolidado (países de capitalismo avançado e demais nichos no restante do mundo), adaptando as estruturas produtivas a padrões mais "flexíveis" de consumo, em que a variedade e a crescente personalização dos produtos viria associada à sua condição de utilidade "descartável ", o que permitiria manter (e ampliar) o ciclo de reprodução do capital. Uma produção, portanto, adaptada à nova dinâmica e lógica de um mercado tendencialmente inelástico em termos horizontais, mas altamente dinâmico e promissor quando direcionado aos (restritos) estratos sociais capazes de consumir em graus cada vez mais diferenciados. Conseqüentemente, "vastos segmentos da população podem ser ignorados sem risco algum pelo desenvolvimento capitalista, mesmo nos países 'avançados', para não mencionar o resto do mundo mantido em subdesenvolvimento forçado" (MÉSZÁROS, 1989, p. 70).

Tais limites estruturais do capitalismo global, ainda que acentuados outros aspectos envolvidos no processo, parecem compor também os horizontes do sociólogo alemão Robert Kurz. Segundo esse autor, com o desenvolvimento da automatização dos processos de trabalho (ou na esteira das tendências impostas por esse modelo produtivo, como é o caso do taylorismo), ter-se-ia estabelecido, pela primeira vez (na história), "olimite lógico inerente ao movimento de exploração abstrata da força de trabalho" (KURZ, 1993b, p. 191), traduzido no fenômeno (que se tornou um problema permanente da sociedade mundial) do desemprego em massa (estrutural). A tese de Kurz é a de que: 
"a acumulação primitiva não chegou a terminar sua obra. Ficou parada na metade do caminho, isto é, depois de desarraigar as massas, deixou de integrá-las na moderna máquina de exploração em empresas. Desde o príncipio, a industrialização foi apenas seletiva, limitando-se a algumas fábricas isoladas que produzem para o mercado mundial[...] A maior parte da sociedade foi apenas modernizada em sentido negativo, isto é, foram destruídas as estruturas tradicionais sem que alguma coisa ocupasse seu lugar [...] O que hoje fz sofrer as massas do Terceiro Mundo não é a provada exploração capitalista de seu trabalho produtivo, conforme continua acreditando, de acordo com a tradição, a esquerda, mas sim, ao contrário, a ausência dessa exploração" (KURZ, 1993b, p.194)

Independentemente dessa visão catastrófica (ou realista?), que prevê para a sociedade burguesa mundial a entrada numa "era das trevas, do caos e da decadência das estruturas sociais, tal como jamais existiu na história do mundo" (KURZ, 1993b, p. 222), a exclusão das massas e o desemprego estrutural (concebido em sua dimensão tendencialmente mundial) compõem a tela de fundo sobre a qual o capital ensaia, em novas composições de cores, os desenhos possíveis de sua reelaboração "estética". Nessa encenação, o taylorismo aparece na melhor das hipóteses como uma alternativa de pacto entre os donos dos meios de produção e a força de trabalho que ainda se sente "privilegiada" por "poder ser explorada", mediante novas cláusulas de direitos e deveres, se possível acordadas após o solapamento do Estado de bem-estar e das tradicionais organizações sindicais combativas da era fordista. Tal sentido do movimento do capital tem sido, aliás, insistentemente tematizado nos últimos anos com alguma clareza. Sobre ele diz Harvey:

"O trabalho organizado foi solapado pela reconstrução de focos de acumulação flexível em regiões que careciam de tradições industriais anteriores e pela reimportação para os centros mais antigos das normas e práticas regressivas estabelecidas nessas novas áreas. A acumulação 
flexível parece implicar níveis relativamente altos de desemprego 'estrutural' (em oposição a 'friccional'), rápida destruição e reconstrução de habilidades, ganhos modestos (quando há) de salários reais e retrocesso do poder sindical - uma das colunas políticas do regime fordista. O mercado de trabalho, por exemplo, passou por uma radical reestruturação. Diante da forte volatilidade do mercado, do aumento da competição e do estreitamento das margens de lucro, os patrões tiraram proveito do enfraquecimento do poder sindical e da grande quantidade de mão-de-obra excedente (desempregados ou subempregados) para impor regimes e contratos de trabalho mais flexíveis" (HARVEY, 1993 apud IANNI, 1994, p. 4).

Octavio Ianni reforça esse entendimento, atentando para o fato de que, numa sociedade cada vez mais mundializada, modificam-se com extrema rapidez os padrões de sociabilidade, vida cultural e consciência, o que atinge, em conseqüência, os padrões de organização do trabalho e da consciência social forjados no âmbito da sociedade nacional e reprograme, num outro patamar, os desafios a serem enfrentados pelos vários segmentos ou classes, agora destituídos de suas identidades pretéritas:

"O padrão flexível de organização da produção modifica as condições sociais e as técnicas de organização do trabalho, torna o trabalhador polivalente, abre perspectivas de mobilidade social vertical e horizontal, acima e abaixo, mas também intensifica a tecnificação da força produtiva do trabalho, potenciando-a. O trabalhador é levado a ajustar-se às novas exigências da produção de mercadoria e excedente, lucro ou mais-valia. Em última instância, o que comanda a flexibilização do trabalho e do trabalhador é um novo padrão de racionalidade do processo de reprodução ampliada do capital, lançado em escala global " (IANNI, 1994, p. 5).

Se o fordismo, nos anos que se seguiram ao pós-guerra, representou a internacionalização do modelo norte-americano de gestão do trabalho enquanto momento de racionalização do processo 
de reprodução ampliada (mundial) do capital em um contexto de franca expansão do mercado (pela incorporação de fatias consideráveis da classe trabalhadora ao mercado de consumo), o toytismo parece encarnar a tática de crescimento seletivo do capital num contexto de retração do mercado mundial e de subproletarização da classe trabalhadora, consagrando uma espécie de modelo de capitalismo pensado pelo avesso, renovado em suas estratégias de maximização da exploração da classe trabalhadora num contexto de refluxo do movimento operário mundial. Gounet, que já fez a crítica de Coriat, mostrou recentemente que "le fondement de la politique de Toyota est de travailler avec un minimum d'ouvriers qui font un maximum d'heures supplémentaires" (GOUNET, 1991, p. 41). Traduzindo-se isso em dados bastante concretos: enquanto o operário de uma montadora na Bélgica (Ford-Genk, General-Motors-Anvers, Volkswagen-Forest, Renault-Vilvorde e Volvo-Gand) trabalha em média de 1550 a 1650 horas/ano, seu correspondente Toyota fica na fábrica cerca de 2300 horas num mesmo intervalo, o que faz com que, no Japão, um veículo seja produzido numa média de 19 horas, contra as 36 da média européia. Como tem dito lapidarmente Alain Bihr (1991, p. 91), na nova ordem produtiva, "a 'centralidade' da grande indústria não é abolida, simplesmente ela se transforma" - e com ela as formas de assalariamento. A "fábrica mínima" do modelo toyota, mais "consensual", mais "participativa", é a forma que molda um "novo (velho) tipo humano" (tal como fora preconizado por Gramsci no caso do fordismo), que agora vem "seriado" - como destaca Antunes (1994, p. 28) - "pelo 'envolvimento cooptado' que possibilita ao capital apropriarse do saber e do fazer do trabalho, [que] na lógica da integração toyotista, deve pensar e agir para o capital, para a produtividade". Talvez se pudesse acrescentar que, para além do pensar e agir, é o sentir que se torna a nova e mais profunda dimensão humana que passa a ser subsumida ao capital, o golpe mais refinado de incorporação da subjetividade do trabalhador ao "coração da fábrica".

Se a primeira revolução técnico-industrial (situada entre o final do século XVIII e o início do XIX) promoveu a substituição, na produção, da força física do homem pela energia das máquinas (do vapor à eletricidade) - base material do modo especificamente capitalista de produção e conseqüente subsunção real do trabalho ao capital -, as atuais transformações radicais resultantes da revolução da microeletrônica e da energia termonuclear representam, no âmbito do capitalismo, a substituição por autômatos das capacidades intelectuais do homem, ampliadas pelas conquistas da ciência e da tecnologia de última geração. O que poderia ser a base material para o grande salto 
qualitativo da sociabilidade humana, do desenvolvimento livre das individualidades, pela redução do trabalho necessário a um mínimo e pela possibilidade definitivamente real de potenciação de outras faculdades humanas (artística, estética, afetiva...) - vislumbradas por Marx (19-- , p. 73-75 e p. 91-94) como possibilidades históricas criadas pelas conquistas técnico-científicas no âmbito do próprio capitalismo -, vai-se constituindo, por uma "dialética negativa" (conforme desenhada por Adorno e Horkheimer), num reforço da "jaula de ferro" weberiana. As perspectivas que se avizinham de novos conflitos embutidos na crise do capital recolocam na ordem do dia a "velha" e sempre nova formulação de Rosa Luxemburgo: socialismo (ou qualquer outra designação que aponte para além do capital) ou barbárie. Diante de uma burguesia - como observa Mandel (1990, p. 299) - "cada vez mais inclinada a uma política de redução do emprego e dos salários diretos e indiretos, especialmente sob pressão do déficit das finanças públicas que se agrava generalizadamente" (esta a raiz da chamada flexibilização), as possibilidades que se abrem poderão ser kurzianamente catastróficas. Tal perigo é também apontado por Adam Schaff (ainda que esse autor seja menos "pessimista") quando registra que "os avanços da automação e da robotização nos países industrializados faz com que estes países reduzam seus investimentos no Terceiro Mundo e até mesmo retirem os investimentos já realizados" (SCHAFF, 1993, p. 89). E ainda que essa tese em particular careça de comprovação empírica mais forte, resta considerar ainda a hipótese de que, uma vez mantidos os investimentos nos países periféricos (ou até mesmo ampliados), os pacotes tecnológico-industriais impor-se-ão à revelia da oferta proporcional necessária de empregos, mundializando o fenômeno da fragmentação do proletariado e da precarização crescente das condições de trabalho. O novo quadro, assim, forçará os atores sociais a se posicionar diante do novo quadro da História. Ver-se-á - como sublinha Bihr (1991, p. 90) - o desenvolvimento de reações corporativas por parte dos trabalhadores que ficaram estáveis e garantidos no emprego frente àqueles precarizados, subempregados, privilegiandose posições adquiridas em detrimento da unidade de classe ou, al di là da heterogeneidade, da fragmentação e da complexificação atualmente presentes no mundo do trabalho, a classe-que-vive-do-trabalho (para utilizar uma categoria de Antunes (1994)) encontrará novas estratégias de identidade que unifiquem a totalidade do trabalho, equacionando num patamar também superior as diferenças de região, cultura, gênero, etnia, assalariamento, etc.?

Enquanto as novas coordenadas se desenham (ainda que não nitidamente) no horizonte, refazem-se sob outras vestes (mais 
"flexíveis") os velhos sonhos fordistas - como diria Simon Clarke (1990) -, inscritos porém, hoje como outrora, no mito de uma utopia inalcançável no interior da moldura da civilização burguesa, e que restam, no máximo, na razão direta de sua própria alucinação, como verdadeiras miragens no deserto das contradições universais genuinamente global.

CORIAT, B. Pensar pelo avesso: o modelo japonês de trabalho e organização. Trad. de Emerson S. da Silva. Rio de Janeiro: Revan, 1994.

FURTADO, C. Globalização das estruturas econômicas e identidade nacional. Política Externa, São Paulo, v. 1, n. 4, p.3-10, 1993.

GOUNET, Thomas. Luttes concurrentielles et stratégies d'accumulation dans l'industrie automobile. Études Marxistes, Paris, n. 10, 1991.

HARVEY, D. Condição pós-moderna. Trad. de Adail U. Sobral e Maria Stela Gonçalves. São Paulo: Loyola, 1993.

IANNI, O. O mundo do trabalho. São Paulo em Perspectiva (Trabalho, globalização e tecnologia), São Paulo, v. 8, n. 1, p.2-12, 1994.

KURZ, R. O colapso da modernização. 2. ed. Trad. de Karen Elsabe Barbosa. Rio de Janeiro: Paz e Terra, 1993a.

KURZ, R. As luzes do mercado se apagam: as falsas promessas do neoliberalismo ao término de um século em crise. Estudos Avançados, São Paulo, n. 18, p.7-41, $1993 b$.

LÊNIN, V. I. O imperialismo: fase superior do capitalismo. In: LÊNIN, V. I. Obras escolhidas. São Paulo: Alfa-Omega, 1977, v. 1. 


\section{REFERÊNCIAS}

ANTUNES, Ricardo. Para onde vai o mundo do trabalho? Campinas: Unicamp, 1994. Mimeografado.

BIHR, Alain. Du "grand soir" à "l'alternative": le mouvement ouvrier européen en crise. Paris: Les Éditions Ouvrières, 1991.

BOYER, R.; MISTRAL, J. La crise actuelle: d'une analyse historique à une vue prospective. Paris: Cepremap, 1983.

BUKHARINE, N. Imperialismo e acumulação de capital. In: LUXEMBURGO, R.; BUKHARINE, N. Imperialismo e acumulação de capital. Lisboa: Edições 70, 1976. p. 271-292.

CASTRO, Nadya Araújo de. Reestruturação produtiva e relações industriais: desafios e interpretações à luz do debate norte-americano atual. Revista Brasileira de Ciências Sociais, São Paulo, v. 11, n. 31, p. 11-122, jun. 1996.

CHESNAIS, F. La mondialisation du capital. Paris: Syros, 1994.

CLARKE, Simon. New Utopias for Old: Fordist Dreams and Post-Fordist Fantasies. Capital G Class Review, London, n. 42, Winter 1990.

COLLINGSWORTH, Terry; GOOLD, J. William; HARVEY, Pharis J. Labor and Free Trade: Time for A Global New Deal. Foreign Affairs Review, [S.l.], v. 73, n. 1, p. 8-13, jan./fev. 1994.

IANNI, O. Globalização e imperialismo. Crítica Marxista, São Paulo, v. 1, n. 3, p. 130-131, 1996.

KURZ, R. As luzes do mercado se apagam: as falsas promessas do neoliberalismo ao término de um século em crise. Estudos Avançados, São Paulo, n. 18, p. 7-41, 1993.

KURZ, R. O colapso da modernização. 2. ed. Trad. de Karen Elsabe Barbosa. Rio de Janeiro: Paz e Terra, 1993.

LÊNIN, V. I. O imperialismo: fase superior do capitalismo. In: LÊNIN, V. I. Obras escolhidas. São Paulo: Alfa-Omega, 1977, v. 1. 
MANDEL, Ernest. A crise do capital. Trad. de Juarez Guimarães e João Machado Borges. São Paulo: Ensaio/UNICAMP, 1990.

MANDEL, Ernest. Late Capitalism. London/New York: Verso, 1993.

MARX, K. A ideologia alemã. 3. ed. Trad. de Conceição Jardim e Eduardo Lúcio Nogueira. Lisboa: Presença/Martins Fontes, 1975, v. 1.

MARX, K. Contribuição à crítica da Economia Política. Trad. de Maria Helena B. Alves. São Paulo: Martins Fontes, 1977.

MARX, K. O Capital. London: Penguin Books, 1981, v. 3.

MARX, K. A natureza interna do capital. In: MARX, K. Elementos fundamentales para la critica de la Economia Politica (Grundrisse) 1857-1858. 14. ed. México: Siglo Veintiuno, 1986.

MARX, K.; ENGELS, F. China: fósil viviente o transmisor revolucionario? México: Universidad Nacional Autonoma de México, 1975.

MÉSZÁROS, István. Produção destrutiva e Estado capitalista. Trad. de Georg Toscheff. São Paulo: Ensaio, 1989.

MICHALET, Charles-Albert. Le capitalisme mondial. Paris: Presses Universitaires de France (PUF), 1976.

PIORE, M.; SABEL, C. The Second Industrial Divide. New York: Basic Books, 1984.

SCHAFF, Adam. A sociedade informática. 4. ed. Trad. de Carlos Eduardo Jordão Machado e Luiz Arturo Obojes. São Paulo: Editora UNESP/ Brasiliense, 1993.

SWEEZY, P. Modern Capitalism. In: SWEEZY, P. Modern Capitalism and Other Essays. New York/London: Monthly Review Press, 1972. cap. 1. 